\title{
Phytochemical Composition, Antiradical and Anticholinesterase Potentials of Centaurea alba and Centaurea jacea Volatile Oils
}

\author{
Olivera Politeo, ${ }^{*}$ Ivana Carev, Anita Veljaca
}

Faculty of Chemistry and Technology, University of Split, Ruđera Boškovića 35, HR-21000 Split, Croatia
${ }^{*}$ Corresponding author's e-mail address: olivera@ktf-split.hr

RECEIVED: November 20, 2018 * REVISED: January 10, 2019 * ACCEPTED: January 15, 2019

Abstract: This paper reports on the phytochemical composition as well as antiradical and anticholinesterase potential of volatile oils isolated from Centaurea alba and Centaurea jacea, from Croatia. The volatile components, obtained by hydrodistillation, were determined by GC and GC-MS analyses. A total of 18 compounds were identified in C. alba volatile oil with hexadecanoic acid, germacrene D and tetradecanoic acid as main compounds. A total of 29 compounds were identified in C. jacea volatile oil, with epi-bicyclosesquiphellandrene, aromadendrene and hexadecanoic acid as a major compounds. The tested volatile oils showed low DPPH inhibition potential as well as low to moderate antiAChE potential and low antiBuChE potential.

Keywords: Centaurea alba L., Centaurea jacea L., volatile oil, GC-MS, DPPH, AChE, BuChE

\section{INTRODUCTION}

$\mathbf{T}$ HE genus Centaurea $\mathrm{L}$. is one of the richest genera in the Asteraceae family. According to today's concept, genus contains about 250 species which have the main spreading area in the Mediterranean region. ${ }^{[1,2]}$

The genus Centaurea had been extensively used in folk medicine for hundreds of years, especially in eastern Mediterranean ethnopharmacology. ${ }^{[3-5]}$ It is confirmed that noumerous Centaurea species have biological potential, as antimicrobial, antifungal, antiviral, antiHelicobacter pylori, antiulcerogenic, antioxidant, antiinflammatory and cytotoxic. ${ }^{[3,6-13]}$

Plants are good source of volatile components that are important in biological and ecological terms. These compounds could be good antioxidants or cholinesterase inhibitors. Antioxidants are compounds that delay autoxidation by inhibiting formation of free radicals or by interrupting propagation of the free radicals. Free radicals alter the structure and function of substances in the body and in high concentrations they can damage proteins, lipids and DNA. The brain is particularly susceptible to oxidative damage. There is substantial evidence that oxidative damage to the brain is an early event in Alzheimer's disease (AD). Many biochemical mechanisms have been proposed to explain the neuropathology of AD but cholinergic hypothesis is the most accepted theory nowadays. It postulates that at least some of the cognitive decline experienced by patients with $A D$ results from a deficiency of acetylcholine, or cholinergic neurotransmission. ${ }^{[14]}$ Neutralizing free radicals and inhibition of acetylcholinesterase (AChE) and butyrylcholinesterase (BuChE) has become an important and persuasive therapeutic strategy against AD. ${ }^{115]}$

As a part of our research on the phytochemical composition and biological potential of Croatian Centaurea sp. ${ }^{[16-18]}$ we report here the results of phytochemical composition as well as antiradical and anticholinesterase potential of Centaurea alba L. and Centaurea jacea L. volatile oils from Croatia.

According to our knowledge, this is the first report about chemical composition of Centaurea alba L. and the second report about chemical composition of Centaurea jacea $\mathrm{L}$. volatile oil, but the first one for the plant from Croatia. This is also the first record about biological potential of these oils. 


\section{EXPERIMENTAL}

\section{Plant Materials}

Plant materials were collected during flowering period in a full blooming phase near Split, Croatia (C. alba L. was collected in Klis, while $C$. jacea L. was collected in Blaca, Kozjak). Plant material were and taxonomically identified by a botanist dr. Mirko Ruščić, associate professor, Department of Biology, Faculty of Science, Split, Croatia. Voucher specimens of plant materials have been deposited in herbarium at the Department of Biochemistry, Faculty of Chemistry and Technology, Split, Croatia and assigned as fellows: 10-2016-CA and 3-2016-CJ.

\section{Materials}

Analytical grade reagents and solvents: 2,2-diphenyl-1-picrylhydrazyl (DPPH) and Ascorbic acid were purchased from Sigma-Aldrich (St. Louis, SAD); Acetylcholinesterase (AChE, from Electrophorus electricus - electric eel, type V-S), Butyrylcholinesterase (BuChE, from equine serum), Acetylthiocholine iodide (ATChI), Butyrylthiocholine iodide (BuTChl), 5,5-dithiobis (2-nitrobenzoicacid) (DTNB, Ellman's reagent) and Eserine were purchased from Sigma-Aldrich $\mathrm{GmbH}$ (Steinheim, Germany); Ethanol was purchased from Kemika, Croatia; Double deionised water was also used.

\section{Volatile Oils Isolation}

The air dried aerial parts of plants were subjected to hydrodistillation using a Clevenger-type apparatus ${ }^{[19]}$ for $3 \mathrm{~h}$. The obtained volatile oils were stored in a sealed vial, under $-20^{\circ} \mathrm{C}$ until use.

\section{Gas Chromatography (GC) and Gas Chromatography-Mass Spectrometry (GC-MS) Analyses}

GC and GC-MS analyses of isolated volatile oils were performed using Varian Inc. Gas Chromatograph, model 3900, Lake Forest, CA, SA, equipped with flame ionization detector and mass detector, model $2100 \mathrm{~T}$, with nonpolar capillary column VF-5MS ( $30 \mathrm{~m} \times 0.25 \mathrm{~mm}$ i.d.; coating thickness $0.25 \mu \mathrm{m})$. Temperature program for VF-5MS column was: $60{ }^{\circ} \mathrm{C}$ isothermal for $3 \mathrm{~min}$, than increased to $246{ }^{\circ} \mathrm{C}$ at a rate of $3{ }^{\circ} \mathrm{C} \mathrm{min}-1$ and held isothermal for $25 \mathrm{~min}$. Carrier gas was helium at flow rate $1 \mathrm{~mL} \mathrm{~min} \mathrm{~m}^{-1}$, injector temperature was $250^{\circ} \mathrm{C}$, injected volume $1 \mu \mathrm{L}$; split ratio of $1: 20$; FID detector temperature was $300^{\circ} \mathrm{C}$. Mass spectrometer ionization voltage was $70 \mathrm{eV}$, mass scan range: 40-350 mass units and ion source temperature was $200{ }^{\circ} \mathrm{C}$. Identification of volatile oils chemical composition was based on comparison of compound mass spectra with databases (Wiley 7 library - Wiley, New York, NY, USA; Adams 2007) and comparison of their retention indices (relative to series of $n$-alkanes $\left.C_{8}-C_{40}\right)$, with internal database retention indices and literature retention indices using NIST2002 (National Institute of Standards and Technology, Gaithersburg, MD, USA). ${ }^{[20,21]}$ The internal database of compounds was created during previous analyses from authentic compounds obtained commercially and from more than thousand volatile oils obtained during our previous studies. The percentages of components were calculated as mean values from the GC and GC-MS peak areas.

\section{Antiradical Potential of Tested Extracts}

Antiradical potential of volatile oils isolated from $C$. alba and $C$. jacea was performed by DPPH (2,2-diphenyl-1-picrylhydrazyl radical scavenging method) method of BrandWilliams et al.[22]. The DPPH radical scavenging activities of the tested extracts were calculated according to formula: \% inhibition $=\left[\left(A_{0}-A_{\text {sample }}\right) / A_{0}\right] \times 100$, where $A_{0}$ was absorbance of the DPPH ethanol solution measured at the beginning and $A_{\text {sample }}$ was absorbance of the sample measured after $60 \mathrm{~min}$. The results were expressed as percentage inhibition of DPPH or $\mathrm{IC}_{50}$ (amount of antioxidant required for $50 \%$ decrease in initial DPPH concentration).Ascorbic acid (vitamin C) was used as positive control. The experiment was performed in triplicate and the results were expressed as mean \pm standard deviations.

\section{Anticholinesterase Potential of Volatile Oils}

Antiacetylcholinesterase (antiAChE) and antibutyrylcholinesterase (antiBuChE) potential of volatile oils isolated from $C$. alba and $C$. jacea were carried out by a slightly modified Ellman method. ${ }^{[23]} \mathrm{A}$ run consisted of $180 \mu \mathrm{L}$ of phosphate buffer (0.1 M, pH 8), $10 \mu \mathrm{L}$ of DTNB (at a final concentration of $0.3 \mathrm{mM}$ prepared in $0.1 \mathrm{M}$ phosphate buffer $\mathrm{pH} 7$ with $0.12 \mathrm{M}$ sodium bicarbonate added for stability), $10 \mu \mathrm{L}$ of sample solution (dissolved in $80 \% \mathrm{EtOH}$ ), and $10 \mu \mathrm{L}$ of AChE/BChE solution (with final concentration $0.03 \mathrm{U} \mathrm{mL}^{-1}$ ). Reactants were mixed in a 96-well plate wells and reaction was initiated by adding $10 \mu \mathrm{L}$ of acetylthiocholine iodide / butyrylthiocholine iodide (ATChl / BTChl, to reach a final concentration of $0.5 \mathrm{mM}$ ). As a negative control, $80 \% \mathrm{EtOH}$ was used instead of sample solution. Non-enzymatic hydrolysis was also monitored by measurement of two blank runs for each run. All spectrophotometric measurements were performed at $405 \mathrm{~nm}$ and at room temperature for 6 min periods. The results are expressed as percentage inhibition of enzyme activity. The experiment was performed in triplicate and the results were expressed as mean \pm standard deviations.

\section{RESULTS AND DISCUSSION}

The volatile oils of two Centaurea species were analyzed by GC and GC-MS. According to my knowledge, this is the first 
report about chemical composition of Centaurea alba and the second report about chemical composition of Centaurea jacea volatile oil, but the first one for the plant from Croatia.

A total of 18 compounds were identified in Centaurea alba volatile oil, representing $98.5 \%$ of the total volatile oil composition, Table 1 . This oil was dominated by nonterpene compounds (61.7\%), especially by nonterpene acids (31.7\%) with hexadecanoic acid $(19.1 \%)$ and tetradecanoic acid $(11.7 \%)$ as main compounds. Nonterpene hydrocarbons $(10.8 \%)$ and aldehydes (9.9\%) were also presented in remarquable quantity. Among them pentadecanal (9.6\%) was presented as the most common. Terpene compounds were presented with sesquiterpenes and sesquiterpenoids in quantity of $36.8 \%$. The main terpene compounds were germacrene $D(14.3 \%)$, hexahydrofarnesyl acetone $(9.3 \%)$ and ledol (5.8\%). Other terpene and nonterpene compounds were identified in quantity lower than $4 \%$

A total of 29 compounds were identified in Centaurea jacea volatile oil, representing $91.1 \%$ of the total volatile oil composition, Table 1. Sesquiterpene compounds (65.9\%) were the most abundant compounds of tested oil with epi-bicyclosesquiphellandrene $(18.7 \%)$ and aromadendrene $(12.5 \%)$ as major ones. $\beta$-Elemene $(8.0 \%)$ and caryophyllene oxide (6.6\%) was also identified in remarkable quantity. Nonterpene compounds were presented in

Table 1. Volatile oil composition of Centaurea alba and Centaurea jacea from Croatia.

\begin{tabular}{|c|c|c|c|c|c|c|c|c|c|}
\hline Compound & $\mathrm{KI}$ & Identification & C. alba & C. jacea & Compound & KI & Identification & C. alba & C. jacea \\
\hline Hexanal & 805 & $\mathrm{KI}, \mathrm{MS}$ & 0.3 & 0.8 & caryophyllene oxide & 1580 & $\mathrm{KI}, \mathrm{MS}$ & 1.9 & 6.6 \\
\hline Octanal & 1006 & $\mathrm{KI}, \mathrm{MS}$ & - & 0.4 & humulene epoxyde II & 1608 & $\mathrm{KI}, \mathrm{MS}$ & - & 1.2 \\
\hline 2,4-heptadienal* & 1013 & $\mathrm{KI}, \mathrm{MS}$ & - & 1.2 & $\alpha$-cadinol & 1653 & $\mathrm{KI}, \mathrm{MS}$ & - & 2.1 \\
\hline benzene acetaldehyde & 1049 & $\mathrm{KI}, \mathrm{MS}$ & - & 1.4 & pentadecanal & 1712 & $\mathrm{KI}, \mathrm{MS}$ & 9.6 & - \\
\hline nonanal & 1102 & $\mathrm{KI}, \mathrm{MS}$ & - & 0.9 & $\alpha$-cyperone & 1750 & $\mathrm{KI}, \mathrm{MS}$ & 3.8 & - \\
\hline$\beta$-cyclocitral & 1214 & $\mathrm{KI}, \mathrm{MS}$ & - & 0.3 & tetradecanoic acid & 1787 & $\mathrm{KI}, \mathrm{MS}$ & 11.7 & - \\
\hline pulegone & 1244 & $\mathrm{KI}, \mathrm{MS}$ & - & 0.3 & $\begin{array}{l}\text { hexahydrofarnesyl } \\
\text { acetone }\end{array}$ & 1845 & $\mathrm{KI}, \mathrm{MS}$ & 9.3 & - \\
\hline anethole & 1283 & $\mathrm{KI}, \mathrm{MS}$ & - & 0.2 & pentacanoic acid & 1882 & $\mathrm{KI}, \mathrm{MS}$ & 0.9 & - \\
\hline bicycloelemene & 1336 & $\mathrm{KI}, \mathrm{MS}$ & - & 4.4 & hexadecanoic acid & 1977 & $\mathrm{KI}, \mathrm{MS}$ & 19.1 & 8.8 \\
\hline$\delta$-elemene & 1340 & $\mathrm{KI}, \mathrm{MS}$ & - & 0.4 & heneicosane & 2100 & $\mathrm{KI}, \mathrm{MS}$ & 1.1 & - \\
\hline$\alpha$-copaene & 1376 & $\mathrm{KI}, \mathrm{MS}$ & 3.5 & 1.7 & docosane & 2200 & $\mathrm{KI}, \mathrm{MS}$ & 1.3 & - \\
\hline$\beta$-patchoulene & 1381 & $\mathrm{KI}, \mathrm{MS}$ & - & 1.0 & tricosane & 2300 & $\mathrm{KI}, \mathrm{MS}$ & 2.9 & - \\
\hline$\beta$-cubebene & 1390 & $\mathrm{KI}, \mathrm{MS}$ & - & 1.9 & heptacosane & 2700 & $\mathrm{KI}, \mathrm{MS}$ & 5.5 & - \\
\hline$\beta$-elemene & 1392 & $\mathrm{KI}, \mathrm{MS}$ & - & 8.0 & Terpene compounds & & & 36.8 & 77.4 \\
\hline$\alpha$-calarene & 1428 & $\mathrm{KI}, \mathrm{MS}$ & - & 4.8 & Monoterpenes & & & - & - \\
\hline aromadendrene & 1427 & $\mathrm{KI}, \mathrm{MS}$ & - & 12.5 & Monoterpenoids & & & - & 0.6 \\
\hline cis- $\beta$-farnesene & 1442 & $\mathrm{KI}, \mathrm{MS}$ & - & 1.4 & Sesquiterpenes & & & 25.3 & 65.9 \\
\hline calarene & 1445 & $\mathrm{KI}, \mathrm{MS}$ & - & 1.6 & Sesquiterpenoids & & & 11.5 & 10.9 \\
\hline alloaromadendrene & 1458 & $\mathrm{KI}, \mathrm{MS}$ & - & 2.1 & Diterpenes & & & - & - \\
\hline Y-patchoulene & 1473 & $\mathrm{KI}, \mathrm{MS}$ & 3.0 & 2.3 & $\begin{array}{l}\text { Phenylpropane } \\
\text { compounds }\end{array}$ & & & - & 0.2 \\
\hline germacrene D & 1480 & $\mathrm{KI}, \mathrm{MS}$ & 14.3 & 1.0 & Nonterpene compounds & & & 61.7 & 13.5 \\
\hline $\begin{array}{c}\text { epi- } \\
\text { bicyclosesquiphellandrene }\end{array}$ & 1488 & $\mathrm{KI}, \mathrm{MS}$ & - & 18.7 & Aldehydes & & & 9.9 & 4.7 \\
\hline valencene & 1491 & $\mathrm{KI}, \mathrm{MS}$ & - & 2.9 & Acids & & & 31.7 & 8.8 \\
\hline$\alpha$-selinene & 1498 & $\mathrm{KI}, \mathrm{MS}$ & 3.0 & - & Esters & & & 9.3 & - \\
\hline Y-cadinene & 1519 & $\mathrm{KI}, \mathrm{MS}$ & 1.5 & 1.2 & Hydrocarbons & & & 10.8 & - \\
\hline Ledol & 1561 & $\mathrm{KI}, \mathrm{MS}$ & 5.8 & - & TOTAL & & & 98.5 & 91.1 \\
\hline spathulenol & 1564 & $\mathrm{KI}, \mathrm{MS}$ & - & 1.0 & & & & & \\
\hline
\end{tabular}


lower quantity (13.5 \%) with hexadecanoic acid (8.8\%) as main compound. Other compounds were identified in quantity lower than $5 \%$. The chemical composition of C. jacea essential oil was previously made from Milošević et al. ${ }^{[24]}$ Results of this study showed sesquiterpenoid compounds, among which carryophyllene oxide (23.5\%) and spathulenol $(8.9 \%)$ were the major ones, as well as fatty acids, with 9-octadecanoic acid (8.9\%) and hexadecanoic acid $(6.6 \%)$ as main components.

A literature search showed that Centaurea species were poor in monoterpene and monoterpenoid compounds and rich in fatty acids as well as sesquiterpene and sesquiterpenoid compounds. Among fatty acids, hexadecanoic acid was the most abundant compounds, while among sesquiterpene and sesquiterpenoid compounds germacrene $D, \beta$-caryohyllene, caryophyllene oxide, spathulenol and $\beta$-eudesmol were the most abundant compounds. ${ }^{[24-34]}$ To date, several Centaurea volatile oils chemical analysis for plants from Croatia were performed. Hexadecanoic acid, germacrene $D, \beta$-caryophyllene and caryophyllene oxide were also the most abundant compounds. Hydrocarbon compounds, especially heptacosane, were also identified in significant quantity. ${ }^{[16-18,35-38]}$

Antiradical and anticholinesterase potential of $C$. alba and $C$. jacea volatile oils were also tested. Antiradical potential was tested by DPPH method, ${ }^{[22]}$ while anti AChE and antiBuChE potential was tested by Ellman method, ${ }^{[23]}$ Table 2. DPPH method is widely used for antiradical detection, while Ellman method is widely used for the detection of cholinesterase inhibitors. Both of used methods are sensitive, good repetitive and requeres a little sample material. Results showed low DPPH inhibition potential for both of tested volatile oils $(5.6 \pm 0.3 \%$ for $C$. alba and $4.9 \pm 0.2 \%$ for $C$. jacea) in tested concentration of $1 \mathrm{mg} \mathrm{mL}^{-1}\left(0.048 \mathrm{mg} \mathrm{mL}^{-1}\right.$ in reaction system). For comparison, vitamin $\mathrm{C}$ as reference compound, showed $95.3 \pm 1.7 \%$ inhibition of DPPH, for the same tested concentration. Results for tested cholinesterase inhibition potential showed low to moderate AChE potential

Table 2. Antiradical and anticholinesterase potential of Centaurea alba and Centaurea jacea volatile oils.

\begin{tabular}{|c|c|c|c|}
\hline & DPPH inh. /\% & AChE inh. /\% & BuChE inh. $/ \%$ \\
\hline C. $a l b a \vee O^{(a)}$ & $5.6 \pm 0.3$ & $28.3 \pm 2.8$ & $5.4 \pm 0.9$ \\
\hline C. jacea $\mathrm{VO}^{(a)}$ & $4.9 \pm 0.2$ & $11.7 \pm 0.9$ & $2.6 \pm 0.7$ \\
\hline vitamin $C^{(a)}$ & $95.3 \pm 1.7$ & - & - \\
\hline eserine $^{(b)}$ & - & $92.9 \pm 3.4$ & $77.9 \pm 1.9$ \\
\hline \multicolumn{4}{|l|}{ VO = volatile oil. } \\
\hline \multicolumn{4}{|c|}{$\begin{array}{l}\text { (a) tested concentration was } 1 \mathrm{mg} \mathrm{mL}^{-1}\left(0.048 \mathrm{mg} \mathrm{mL}^{-1} \text { for DPPH and }\right. \\
0.045 \mathrm{mg} \mathrm{mL}^{-1} \text { for AChE / BuChE in reaction system). }\end{array}$} \\
\hline \multicolumn{4}{|c|}{$\begin{array}{l}\text { (b) tested concentration was } 0.1 \mathrm{mg} \mathrm{mL}^{-1}\left(4.8 \mu \mathrm{g} \mathrm{mL} L^{-} \text {for DPPH and }\right. \\
4.5 \mu \mathrm{g} \mathrm{mL} \mathrm{L}^{-1} \text { for AChE / BuChE in reaction system). }\end{array}$} \\
\hline
\end{tabular}

of tested oils $(28.3 \pm 2.8 \%$ for $C$. alba and $11.7 \pm 0.9 \%$ for $C$. jacea) and low BuChE inhibition potential of tested oils (5.4 \pm $0.9 \%$ for $C$. alba and $2.6 \pm 0.7 \%$ for $C$. jacea) for tested concentration of $1 \mathrm{mg} \mathrm{mL} \mathbf{m}^{-1}\left(0.045 \mathrm{mg} \mathrm{mL}^{-1}\right.$ in reaction system). For comparison, eserine as referent compound showed $92.2 \pm 3.4 \%$ inhibition of AChE and $77.9 \pm 1.9 \%$ inhibition of BuChE for tested concentration of $0.1 \mathrm{mg} \mathrm{mL}^{-1}$.

Low DPPH inhibition potential could be connected to composition of these oils which does not contain components attributed to antiradical potential, like phenolic or monoterpenoid compounds. ${ }^{[39]}$ Low to moderate anticholinesterase inhibition potential of tested volatile oils also could be connected to volatile oils composition or synergism among volatile oil constituents. Among volatile compounds identified as components of tested oils, pulegone, anethole, $\alpha$-copaene, aromadendrene, ledol and caryophyllene oxide were tested on AChE, while anethole, $\alpha$ copaene, ledol and caryophyllene oxide were tested on BuChE inhibition. ${ }^{[40]}$ Among them, anethole and pulegone showed good AChE inhibition potential, while only anethole showed good BuChE potential.

\section{CONCLUSION}

The volatile oils of Centaurea alba and Centaurea jacea from Croatia were subjected to phytochemical composition as well as antiradical and anticholinesterase potentials. $C$. alba volatile oil was dominated by nonterpene compounds, especially by nonterpene acids, with hexadecanoic acid and tetradecanoic acid as main compound. Nonterpene hydrocarbons and aldehydes were also presented in remarquable quantity with pentadecanal as most abundant. Terpene compounds were presented with sesquiterpenes and sesquiterpenoids. The main terpene compounds were germacrene $\mathrm{D}$, hexahydrofarnesyl acetone and ledol. C. jacea volatile oil was dominated by sesquiterpene compounds, with epi-bicyclosesquiphellandrene and aromadendrene as major compounds. $\beta$-Elemene and caryophyllene oxide were also identified in remarkable quantity. Nonterpene compounds were presented in lower quantity, with hexadecanoic acid as main compound. Antiradical and anticholinesterase potential of $C$. alba and $C$. jacea volatile oils showed low DPPH inhibition potential for both of tested volatile oils as well as low to moderate AChE and low BuChE inhibition potential of tested oils.

Acknowledgements. The study was financially supported by Croatian Science Foundation under the project IP-2014-096897. We acknowledge the botanical identification of the plant material by PhD Mirko Ruscic, associate professor, Faculty of Science, Department of Biology, University of Split, Croatia. 
Author Contribution Statement. OP designed experiments, performed chemical analyses and wrote manuscript; AV performed biological assays; IC collected plant materials and assisted during the experiments.

\section{REFERENCES}

[1] A. Susanna, N. Garcia-Jacas in The families and genera of vascular plants., Vol. 8, (Ed. K. Kubitzki), Springer Verlag, Berlin, Germany, 2007, pp. 123-146.

[2] A. Susanna, N. Garcia-Jacas in Systematics, evolution, and biogeography of Compositae (Eds. V. A. Funk, A. Susanna, T. F. Stuessy, R. J. Bayer), International Association for Plant Taxonomy, Vienna, Austria, 2009, pp. 293-313.

[3] E. Yeşilada, E. Sezik, G. Honda, Y. Takaishi, Y. Takeda, T. Tanaka, J. Ethnopharmacol. 1999, 64, 195-210. https://doi.org/10.1016/S0378-8741(98)00133-0

[4] R. Arif, E. Küpeli, F. Ergun, Gazi Üniv. Fen Bil. Dergisi, 2004, 17, 149-164.

[5] T. Baytop, in Turkey, Past and Present, $2^{\text {nd }}$ Ed., Nobel Publishers, Istanbul, Turkey, 1999.

[6] A. Khammar, S. Djeddi, Eur. J. Sci. Res. 2012, 84, 398-416.

[7] J. F. Severino, K. Stich, G. Soja, Environ. Pollut. 2007, 146, 707-714.

https://doi.org/10.1016/j.envpol.2006.04.006

[8] C. Karamenderes, S. Khan, B. L. Tekwani, M. R. Jacob, I. A. Khan, Pharm. Biol. 2006, 44, 534-539. https://doi.org/10.1080/13880200600883080

[9] M. Shoeb, S. M. MacManus, M. Jaspars, J. Trevidu, L. Nahar, P. Kong-Thoo-Lin, S. D. Sarker, Tetrahedron 2006, 62, 11172-11177. https://doi.org/10.1016/j.tet.2006.09.020

[10] C. Koukoulitsa, G. D. Geromichalos, H. Skaltsa, J. Comput.-Aided Mol. Des. 2005, 19, 617-623. https://doi.org/10.1007/s10822-005-9018-y

[11] G. Stamatis, P. Kyriazopoulos, S. Golegou, A. Basayiannis, S. Skaltsas, H. Skaltsa, J. Ethnopharmacol. 2003, 88, 175-179. https://doi.org/10.1016/S0378-8741(03)00217-4

[12] N. Garbacki, V. Gloaguen, J. Damas, P. Bodart, M. Tits, L. Angenat, J. Ethnopharmacol. 1999, 68, 235-241. https://doi.org/10.1016/S0378-8741(99)00112-9

[13] G. Rusak, M. Krajacic, N. Plese, Antiviral Res. 1997, 36, 125-129. https://doi.org/10.1016/S0166-3542(97)00045-4

[14] L. A. Craig, N. S. Hong, R. J. McDonal, Neurosci. Biobehav. R. 2011, 35, 1397-1409.

https://doi.org/10.1016/j.neubiorev.2011.03.001

[15] C. Costagli, A. Galli, Biochem Pharmacol. 1998, 55 (10), 1733-1737.

https://doi.org/10.1016/S0006-2952(97)00676-X
[16] I. Carev, A. Maravic, M. Bektasevic, M. Ruscic, S. Siljak-Yakovlev, O. Politeo, Croat. Chem. Acta 2018, 91, 11-18. https://doi.org/10.5562/cca3205

[17] I. Carev, M. Ruscic, M. Skocibusic, A. Maravić, S. SiljakYakovlev, O. Politeo, Chem. Biodivers. 2016, 14, e1600213. https://doi.org/10.1002/cbdv.201600213

[18] O. Politeo, M. Skocibusic, I. Carev, F. Burcul, I. Jerkovic, M. Sarolic, M. Milos, Nat. Prod. Comm. 2012, 7, 1087-1090.

https://doi.org/10.1177\%2F1934578X1200700831

[19] J. F. Clevenger, J. Am. Pharm. Assoc. 1928, 17, 346.

[20] R. P. Adams, Identification of essential oil components by gas chromatography / mass spectrometry, $4^{\text {th }} \mathrm{Ed}$, Allured Publ Corp Carol Stream, IL, USA., 2005.

[21] P. J. Linstrom, W. G. Mallard, NIST Chemistry WebBook, NIST Standard Reference Database Number 69. 2014.

[22] W. Brand-Williams, M. E. Cuvelier, C. Berset, Food Sci. Tech. 1995, 28, 25-30. https://doi.org/10.1016/S0023-6438(95)80008-5

[23] G. L. Ellman, K. D. Courtney, V. Andres, R. M. Featherstone, Biochem. Pharmacol. 1961, 7, 88-90. https://doi.org/10.1016/0006-2952(61)90145-9

[24] T. Milosevic, C. Argyropoulou, S. Solujic, D. MuratSpahic, Nat. Prod. Comm. 2010, 5, 1663-1668. https://doi.org/10.1177\%2F1934578X1000501030

[25] J. Novakovic, N. Rajcevic, S. Milanovici, P. D. Marin, P. Janackovic, Chem. Biodivers. 2016, 13, 1221-1229. https://doi.org/10.1002/cbdv.201600029

[26] O. Kilic, E. Bagci, J. Essent. Oil Bear. Pl. 2016, 19, 185-193. https://doi.org/10.1080/0972060X.2014.885315

[27] A. Maggio, L. Riccobono, S. Bancheva, M. Bruno, F. Senatore, Nat. Prod. Commun. 2014, 9, 1373-1376. https://doi.org/10.1177\%2F1934578X1400900938

[28] S. B. Erel, B. Demirci, S. Demir, C. Karaalp, H. H. C. Beser, J. Ess. Oil. Res. 2013, 25, 79-84. https://doi.org/10.1080/10412905.2012.755476

[29] G. Zengin, A. Aktumsek, G. O. Guler, Y. S. Cakmak, Y. Kan, Nat. Prod. Res. 2012, 26, 1-10. https://doi.org/10.1080/14786419.2010.527839

[30] C. Formisano, D. Rigano, F. Senatore, S. Bancheva, M. Bruno, A. Maggio, S. Rosselli, Nat. Prod. Commun. 2011, 6, 1339-1342. https://doi.org/10.1177\%2F1934578X1100600930

[31] F. Senatore, N. A. Arnold, M. Bruno, Nat. Prod. Res. 2005, 19, 749-754. https://doi.org/10.1080/14786410412331302136

[32] A. Esmaeilli, A. Rustaiyan, M. Nadimi, J. Ess. Oil. Res. 2005, 17, 539-541. https://doi.org/10.1080/10412905.2005.9698988

[33] H. Dural, Y. Bagci, K. Ertugrul, H. Demirelma, G. Flamini, P. L. Cioni, L. Morelli, Biochem. Syst. Ecol. 2003, 31, 1417-1425. https://doi.org/10.1016/S0305-1978(03)00128-5 
[34] F. Senatore, D. Rigano, R. de Fusco, M. Bruno, Flavour Frag. J. 2003, 18, 248-251.

[35] M. Bruno, A. Milia, G. Catinella, S. Bancheva, Nat. Prod. Commun. 2018, 13, 1179. https://doi.org/10.1177\%2F1934578X1801300920

[36] L. Riccobono, Maggio, M. Bruno, S. Bancheva, O. Santucci, F. Senatore, Plant Byosist. 2017, 51 (6), 1035-1044. https://doi.org/10.1080/11263504.2016.1219419

[37] C. Formisano, F. Senatore, S. Bancheva, M. Bruno, S. Roselli, Croat. Chem. Acta 2010, 83, 403-408.
[38] C. Formisano, F. Senatore, S. Bancheva, M. Bruno, A. Maggio, S. Roselli, Nat. Prod. Commun. 2010, 5, 1649-1654.

https://doi.org/10.1177\%2F1934578X1000501027

[39] F. Bakkali, S. Averbeck, D. Averbeck, M. Idaomar, Food Chem. Toxicol. 2008, 46, 446-475. https://doi.org/10.1016/j.fct.2007.09.106

[40] F. Burčul, I. Blažević, M. Radan, O. Politeo, Curr. Med. Chem. 2019 (Ahead of Print).

https://doi.org/10.2174/0929867325666180330092607 